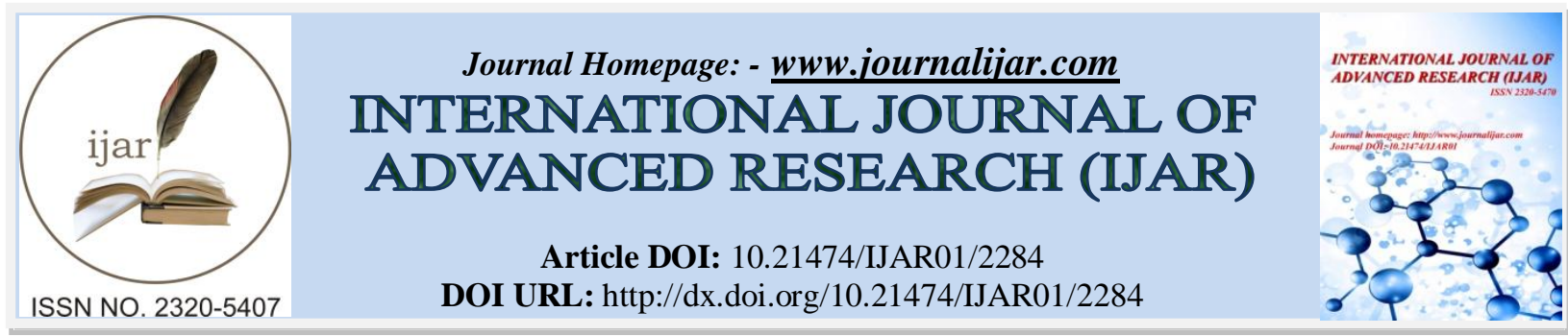

RESEARCH ARTICLE

\title{
RISK ASSESSMENT OF ALZHEIMER DISEASE AMONG ATTENDANTS OF GENERAL HOSPITALS IN AI-QASSIM.
}
"Ibtehal Al-Harbi, Atheer Al-Hujilan, Hajar Al_Akeel, Lina Alyousif, Maha Al-Shetwi, Monira Al-Nasser and Lamees Al-Habeeb. Qassim University, KSA.

\section{Manuscript Info}

Manuscript History

Received: 29 September 2016

Final Accepted: 30 October 2016

Published: November 2016

Key words:-

Alzheimer's disease, risk factors, risk assessment,

\section{Abstract}

Background: Alzheimer's disease is the commonest form of dementia; a general term for memory loss and other intellectual abilities that interferes with daily life. AD accounts for 50 to 80 percent of dementia cases. In Saudi Arabia, there is a lack of information that estimate current prevalence and care costs along with other aspects of the disease. To this regard; we want to recognize risk factors associated with $\mathrm{AD}$ and their significance in SA.

Methods: A Cross sectional study among attendants of general hospitals in Al- Qassim (Buridah, Unizah, Arass) aged between 50-80 male and females. All attendants during the 2 days of data collection were included (72 participants). The questionnaire designed includes: socio-demographic data, risk factors and tool of assessment; SMMSE.

Results: Individuals with higher education had significantly higher scores than their counterparts. Employed individuals, and mental laborers had significantly higher scores than their unemployed and physical workers respectively. Individuals with higher monthly income had significantly higher scores than those with lower income. Individuals who do not have chronic diseases had significantly higher scores than individuals who had chronic diseases (e.g. DM, HTN and heart disease). Individuals who participated more in social activities had significantly higher scores than their counterparts. Individuals who didn't use medications had significantly higher scores than who did.

Conclusions and recommendations: Differences in education level, employment status, type of work, monthly income, chronic diseases association, social activity and use of medications significantly affected the $\mathrm{AD}$ risk score for individuals from 50 to 80 years of age. The impact of $\mathrm{AD}$ in $\mathrm{SA}$ deserves further epidemiological and clinical research to enable early detection, treatment, and caregiver support. Education of individuals at risk about $\mathrm{AD}$, its prevention and about measures to delay its development. Such efforts will promote greater awareness, refine the policy agenda and call for concerted action. 


\section{Introduction:-}

Alzheimer's disease is the most common form of dementia, a general term for memory loss and other intellectual abilities serious enough to interfere with daily life. Alzheimer's disease accounts for 50 to 80 percent of dementia cases. It's is not a normal part of aging, although the greatest known risk factor is increasing age, and the majority of people with Alzheimer's are 65 and older. But Alzheimer's is not just a disease of old age. Up to 5 percent of people with the disease have early onset Alzheimer's (also known as younger-onset), which often appears when someone is in their 40s or 50s. Today, an American develops Alzheimer's disease every 68 seconds. In 2050, an American will develop the disease every 33 seconds. An estimated 5.2 million Americans of all ages have Alzheimer's disease in 2013. This includes an estimated 5 million people age 65 and older and approximately 200,000 individuals younger than age 65 who have younger-onset Alzheimer's. (Alzheimer's association-2013).

According to the WHO, treating and caring for people with dementia currently costs the world more than US\$ 604 billion per year (WHO-2008). This includes the cost of providing health and social care as well the reduction or loss of income of people with dementia and their caregivers. Estimates of the future cost of dementia in Europe is a rise of $43 \%$ from 2008 reaching 250 billion Euros in 2030. It is expected to rise by $43 \%$ between 2008 and 2030 reaching 250 billion Euros in 2030. (WHO-1992).

The more individuals advance in age the higher is the risk they will develop Alzheimer disease. Because more and more people live longer lives this disease is becoming a serious concern. The age-specific incidence rates for Alzheimer disease demonstrate a doubling of incidence for about every six years of added life, which indicates an exponential increasing risk with increasing age. (Medicines for Europe and the World -2013) Another strong risk factor is family history. Those who have a parent, brother, sister or child with Alzheimer's are more likely to develop the disease. The risk increases if more than one family member has the illness. When diseases tend to run in families, either heredity (genetics) or environmental factors, or both, may play a role. In the other hand, several studies indicate a role for environmental effects on AD development. Diabetes, hypertension, smoking, obesity, and dyslipidemia have all been found to increase risk as well a history of brain trauma, cerebrovascular disease, and vasculopathies. . (Alzheimer's association-2013).

In Saudi Arabia, there is a complete lack of information that estimates current prevalence and cost of care as well as other aspects of the disease, such as care settings, treatment, detection, diagnosis and the current understanding of the disease. Patient and caregiver perspectives that may reveal the daily struggle of living and dealing with the disease are missing. The risk factors that associated with $\mathrm{AD}$ (i.e. lifestyle choices and Environmental factors) are not exactly determined (Saudi Alzheimer's disease association). Regarding to this fact about Saudi Arabia, we like to recognize the risk factors associated with Alzheimer's disease and the significance of some factors.

\section{Research Question:}

What is the prevalence of symptoms of Alzheimer among the age group 50 to 80 and the associated risk factors?

\section{Objectives:-}

General Objectives:

To detect the occurrence of Alzheimer symptoms among group of individuals aged

50-80 attended to general hospital in Al- Qassim. ( Buridah, Unizah, Arass )

Specific Objectives:

1. To measure the level of Alzheimer.

2. To assess the associated risk factors.

\section{Methodology:-}

- Study design and setting: A Cross sectional study among attendants of general hospital in Al- Qassim. ( Buridah, Unizah, Arass )

- Study population: Attendants of general Hospital (Arass General Hospital, King Saud hospital, King Fahad specialist hospital) aged between 50-80 male and females.

- Sampling: All the attendants in the age group during the 2 days of data collection were included (72 participants).

- Data Collection: A questionnaire was designed includes: socio-demographic data, risk factors and tool of assessment. SMMSE, a standardized approach to scoring and interpreting older people's cognitive function, 
provides a global score of cognitive ability that correlates with daily function. Careful interpretation of results of the SMMSE, together with history and physical assessment, can assist in differential diagnosis of cognitive impairment resulting from Alzheimer's disease. Repeated measurements can be used to assess change over time and response to treatment. The students in the research group interviewed the participants.

- The aims of the research were explained to the participants and they were assured that their responses to the questionnaires will be confidential. There was no obligation for participation and we had a verbal consent.

Statistical Analysis: All values will be analyzed using software statistical Package of Social Science (SPSS 20 for window- Evaluation version). Descriptive statistics included frequency tables and graphs. Analysis of the data using $\mathrm{X} 2$ test and $\mathrm{P}$ value for comparison between groups.

\section{Discussion and Results:-}

The table below shows the stages of cognitive impairment that relate to SMMSE scores. A total score of 30 indicates no impairment. Scores between 26 and 30 are considered normal in the general population. Patients who score between 25 and 20 have mild cognitive impairment and will be experiencing problems with the instrumental activities of daily living, such as shopping, finances, medication use, and meal preparation, but can usually live on their own with support. Those who score between 20 and 10 have moderate cognitive impairment, usually cannot live independently, and are starting to have problems with basic activities, such as grooming, dressing, and using the toilet. Scores between 9 and 0 denote severe cognitive impairment; patients will be having problems with all basic activities, including eating and walking.

\begin{tabular}{|l|l|l|l|}
\hline \multicolumn{2}{|l|}{ Interpreting results } & Stage & Duration \\
\hline Score & Description & Could be normal & Varies \\
\hline $30-26$ & Could be normal & Early & 0 to 2-3 \\
\hline $25-20$ & Mild & Middle & $4-7$ \\
\hline $19-10$ & Moderate & Late & $7-14$ \\
\hline $9-0$ & Severe & \\
\hline
\end{tabular}

The following tables and figure will discuss the relation of each risk factor to either a high or low score on the MMSE.

Age * Score Level

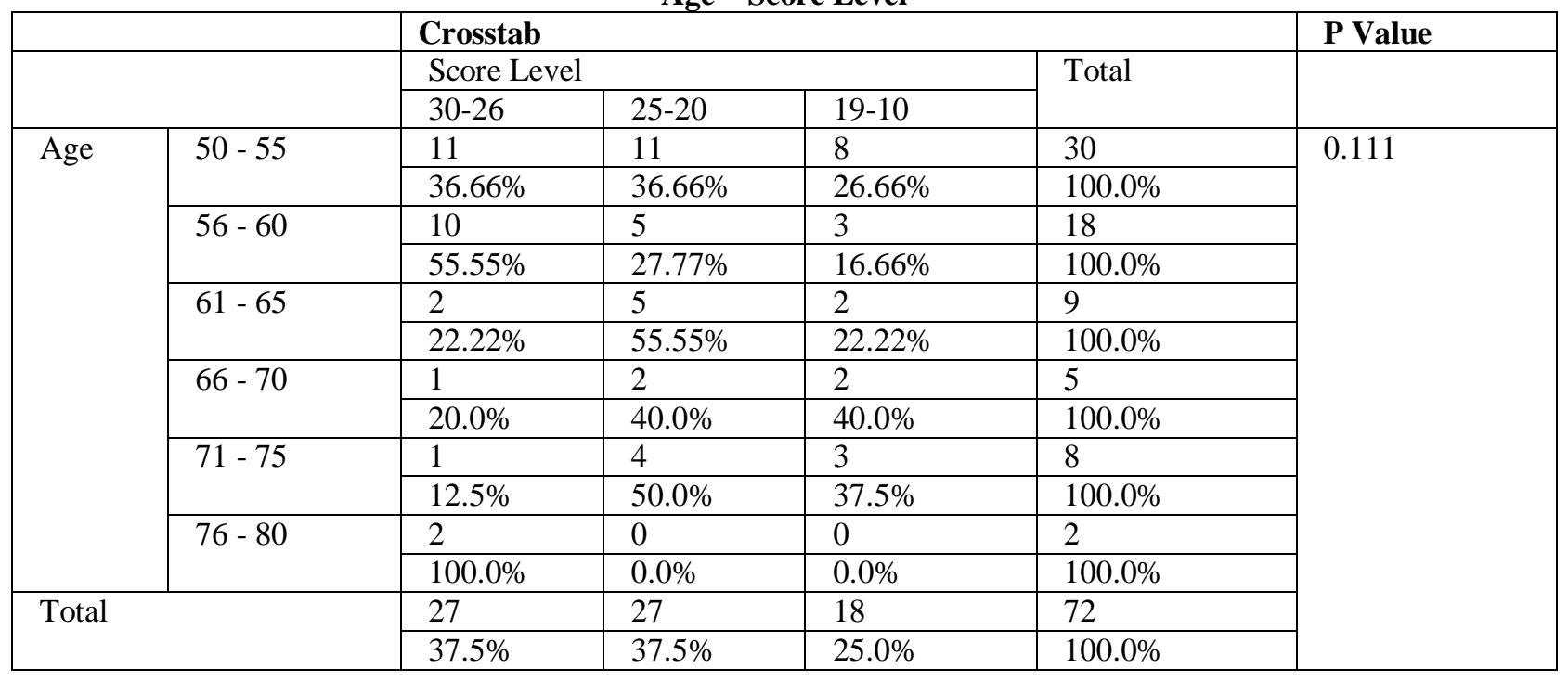




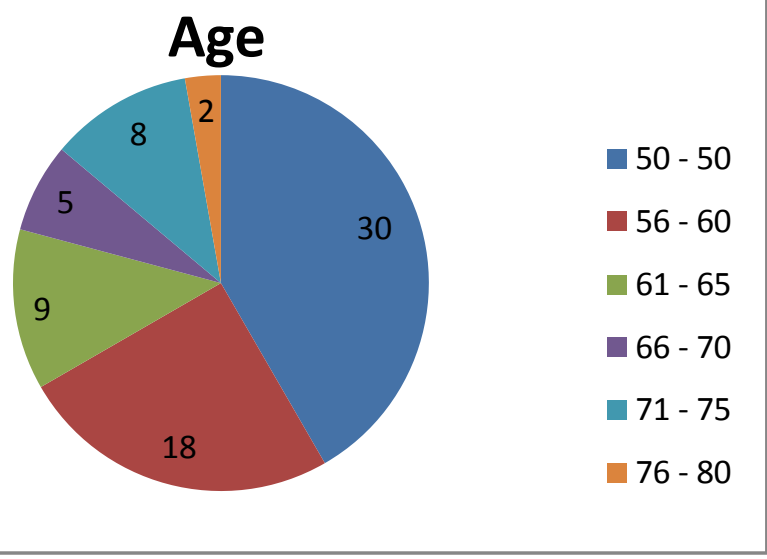

Table 1, Figure 1:

Showed that the age group (50-60) scored in the range (30-26) where the age group (61-70) scored in the range (25$20)$ and the age group (71-80) scored in the range (25-20)

However, the $\mathrm{P}$ value indicates that no significant risk factor was detected.

Sex * Score Level

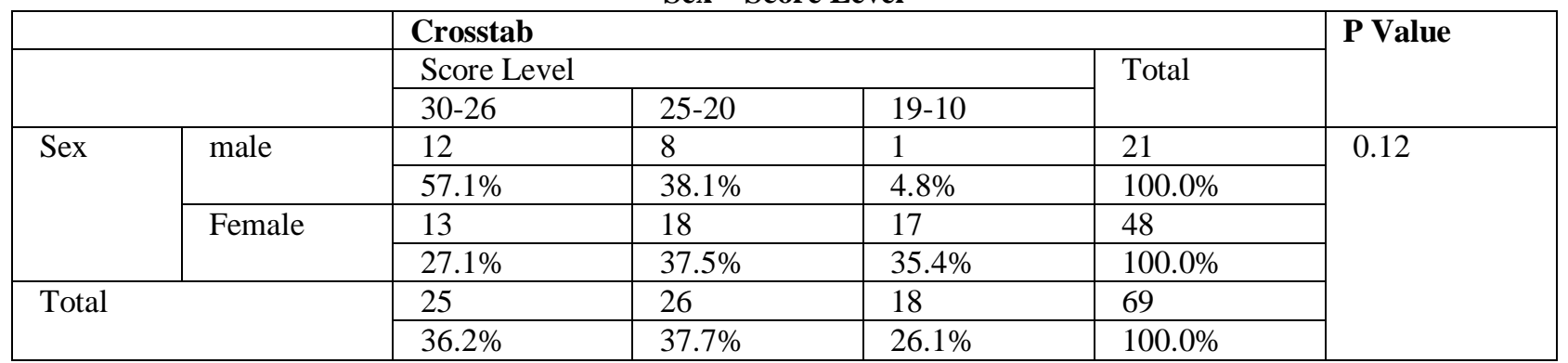

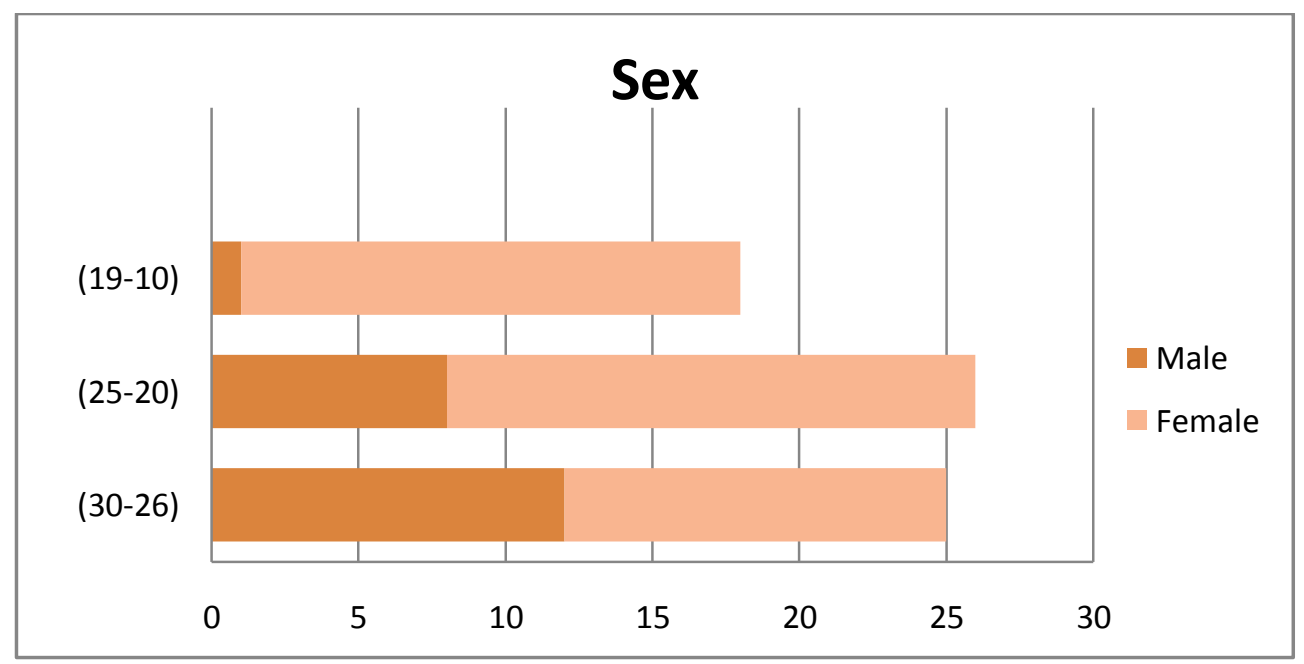

Table 2, Figure 2:

Showed that there was a male predominance in the group that scored (30-26), while there was female predominance in the group that scored (25-20) and (19-10).

However, the $\mathrm{P}$ value indicates that no significant risk factor was detected. 
Marital status * Score Level

\begin{tabular}{|c|c|c|c|c|c|c|}
\hline & & \multicolumn{4}{|c|}{ Crosstab } & \multirow[t]{3}{*}{ P Value } \\
\hline & & \multicolumn{3}{|c|}{ Score Level } & \multirow[t]{2}{*}{ Total } & \\
\hline & & $30-26$ & $25-20$ & $19-10$ & & \\
\hline \multirow[t]{4}{*}{ Marital status } & \multirow[t]{2}{*}{ Married } & 24 & 25 & 14 & 63 & \multirow[t]{6}{*}{0.326} \\
\hline & & $38.1 \%$ & $39.7 \%$ & $22.2 \%$ & $100.0 \%$ & \\
\hline & \multirow[t]{2}{*}{ Not married } & 3 & 2 & 4 & 9 & \\
\hline & & $33.3 \%$ & $22.2 \%$ & $44.4 \%$ & $100.0 \%$ & \\
\hline \multirow{2}{*}{\multicolumn{2}{|c|}{ Total }} & 27 & 27 & 18 & 72 & \\
\hline & & $37.5 \%$ & $37.5 \%$ & $25.0 \%$ & $100.0 \%$ & \\
\hline
\end{tabular}

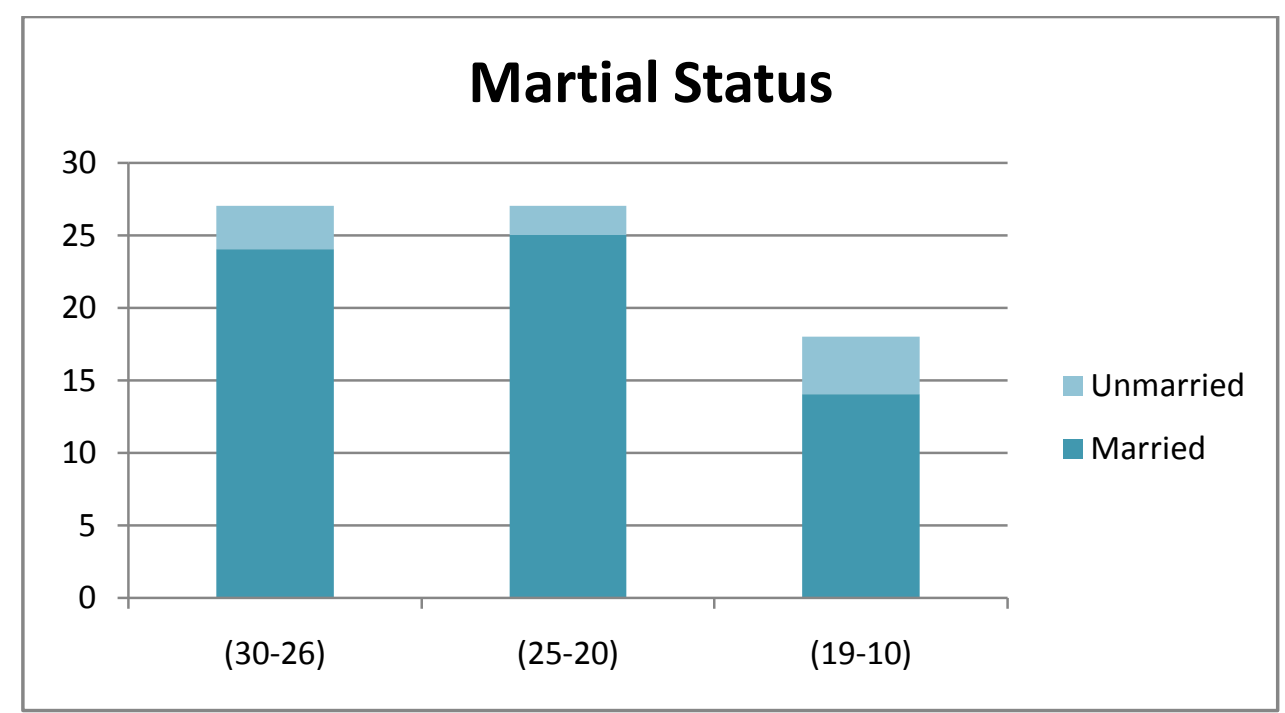

Table 3, Figure 3

Showed that married individuals had scored in the range (25-20) with the percentage of (39.7\%) Where the unmarried group scored in the range (19-10) with the percentage $(44.4 \%)$

However, the $\mathrm{P}$ value indicates that no significant risk factor was detected.

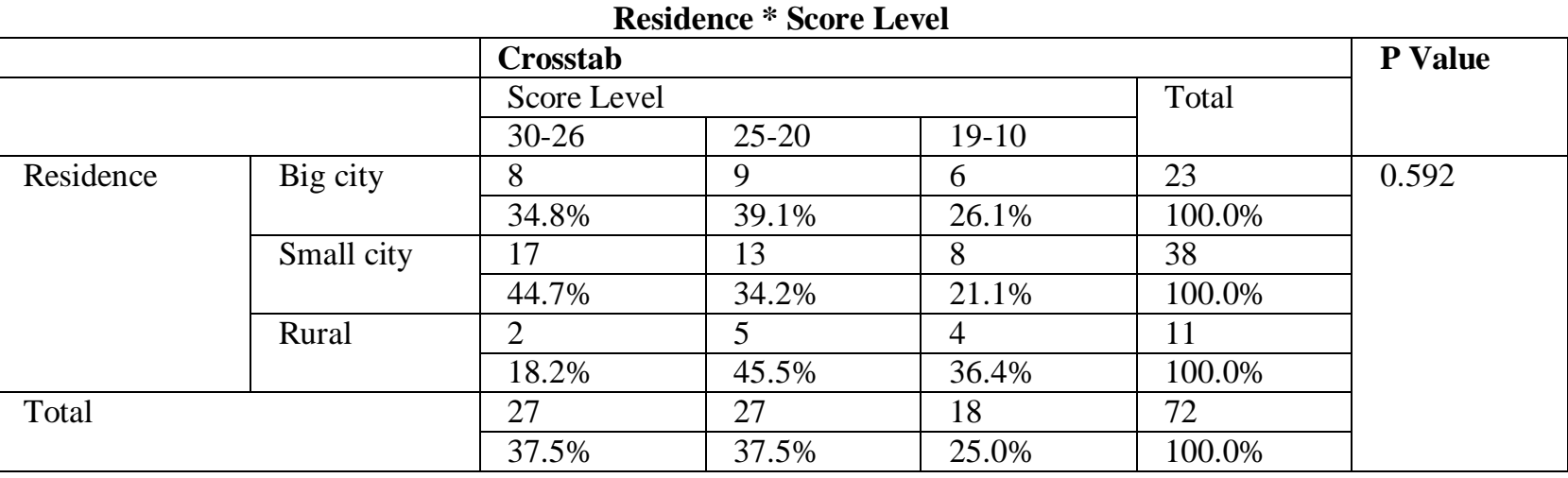




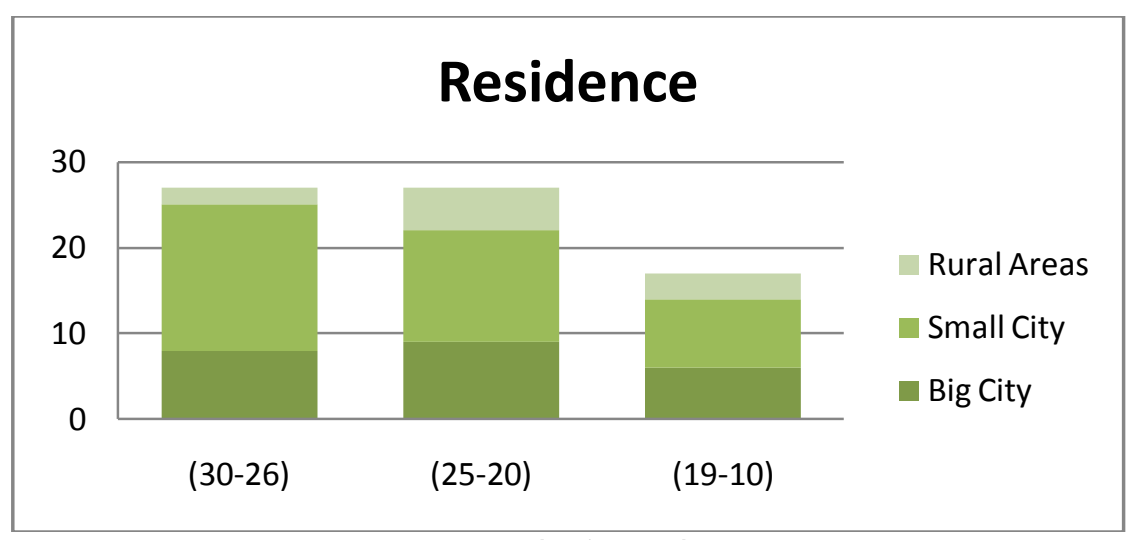

Table 4, Figure 4:

Showed that individuals in big cities scored in the range (25-20) with the percentage of (39.1\%) Where individuals in small cities scored in the range (30-26) with the percentage of (44.7\%) And individuals in rural areas scored in the range (25-20) with the percentage of (45.5\%)

In conclusion: individuals who lived in big and small cities tend to have a higher score than those who lived in rural areas.

However, the $\mathrm{P}$ value indicates that no significant risk factor was detected.

\begin{tabular}{|c|c|c|c|c|c|c|}
\hline \multicolumn{7}{|c|}{ Education level $*$ Score Level } \\
\hline & & \multicolumn{4}{|c|}{ Crosstab } & \multirow[t]{3}{*}{ P Value } \\
\hline & & \multicolumn{3}{|c|}{ Score Level } & \multirow[t]{2}{*}{ Total } & \\
\hline & & $30-26$ & $25-20$ & $19-10$ & & \\
\hline \multirow[t]{12}{*}{ Education level } & \multirow[t]{2}{*}{ Illiterate } & 0 & 7 & 14 & 21 & \multirow[t]{14}{*}{0.000} \\
\hline & & $0.0 \%$ & $33.3 \%$ & $66.7 \%$ & $100.0 \%$ & \\
\hline & \multirow[t]{2}{*}{ Can read and write } & 4 & 4 & 1 & 9 & \\
\hline & & $44.4 \%$ & $44.4 \%$ & $11.1 \%$ & $100.0 \%$ & \\
\hline & \multirow[t]{2}{*}{ Elementary school } & 8 & 8 & 3 & 19 & \\
\hline & & $42.1 \%$ & $42.1 \%$ & $15.8 \%$ & $100.0 \%$ & \\
\hline & \multirow[t]{2}{*}{ Middle school } & 3 & 5 & 0 & 8 & \\
\hline & & $37.5 \%$ & $62.5 \%$ & $0.0 \%$ & $100.0 \%$ & \\
\hline & \multirow[t]{2}{*}{ High school } & 2 & 2 & 0 & 4 & \\
\hline & & $50.0 \%$ & $50.0 \%$ & $0.0 \%$ & $100.0 \%$ & \\
\hline & \multirow[t]{2}{*}{ College } & 10 & 1 & 0 & 11 & \\
\hline & & $90.9 \%$ & $9.1 \%$ & $0.0 \%$ & $100.0 \%$ & \\
\hline \multirow{2}{*}{\multicolumn{2}{|c|}{ Total }} & 27 & 27 & 18 & 72 & \\
\hline & & $37.5 \%$ & $37.5 \%$ & $25.0 \%$ & $100.0 \%$ & \\
\hline
\end{tabular}

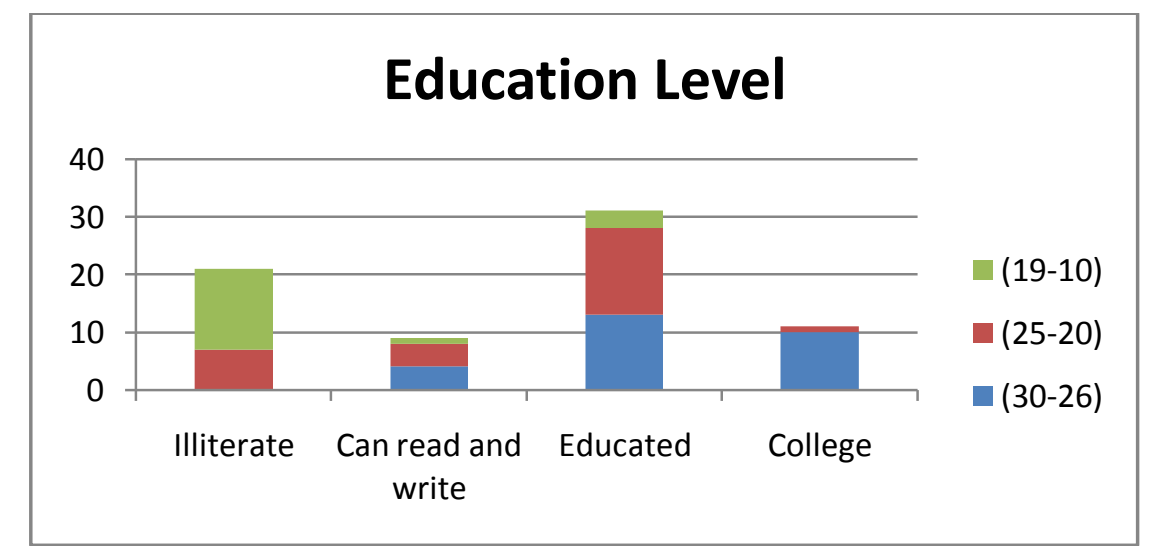

Table 5, Figure 5 
Showed that illiterate individuals were more likely to score in the range (19-10) with the percentage of (66.7\%). Where individuals who can read and write or have some sort of education were more likely to score in the ranges of (30-20).

The $\mathrm{P}$ value indicates that a significant risk factor was detected.

Employment Status * Score Level

\begin{tabular}{|c|c|c|c|c|c|c|}
\hline & & \multicolumn{4}{|c|}{ Crosstab } & \multirow[t]{3}{*}{ P Value } \\
\hline & & \multicolumn{3}{|c|}{ Score Level } & \multirow[t]{2}{*}{ Total } & \\
\hline & & $30-26$ & $25-20$ & $19-10$ & & \\
\hline \multirow{4}{*}{ Employment Status } & \multirow[t]{2}{*}{ Yes } & 16 & 9 & 3 & 28 & \multirow[t]{6}{*}{0.016} \\
\hline & & $57.1 \%$ & $32.1 \%$ & $10.7 \%$ & $100.0 \%$ & \\
\hline & \multirow[t]{2}{*}{ No } & 11 & 18 & 14 & 43 & \\
\hline & & $25.6 \%$ & $41.9 \%$ & $32.6 \%$ & $100.0 \%$ & \\
\hline \multirow{2}{*}{\multicolumn{2}{|c|}{ Total }} & 27 & 27 & 17 & 71 & \\
\hline & & $38.0 \%$ & $38.0 \%$ & $23.9 \%$ & $100.0 \%$ & \\
\hline
\end{tabular}

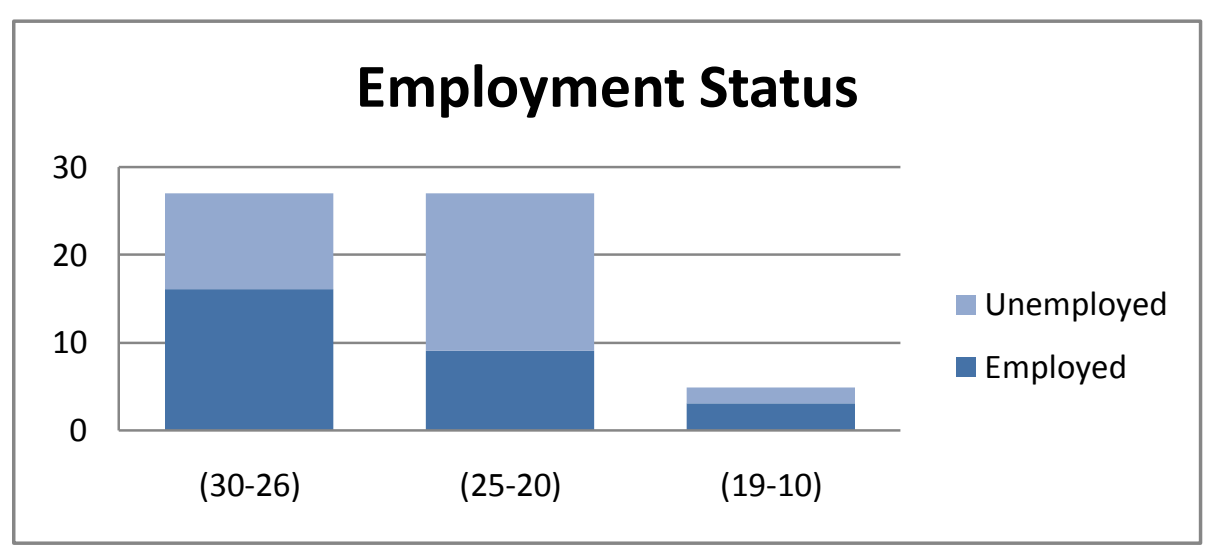

Table 6, Figure 6

Showed that employed individuals scored in the range (30-26) with the percentage of (57.1\%) where unemployed individuals showed an inclination in the ranges (25-20) with a percentage of (41.9\%) and (19-10) with a percentage of $(32.6 \%)$

The $\mathrm{P}$ value indicates that a significant risk factor was detected.

Nature of work * Score Level

\begin{tabular}{|c|c|c|c|c|c|c|}
\hline & \multicolumn{4}{|c|}{ Crosstab } & \multirow[t]{3}{*}{ P Value } \\
\hline & & \multicolumn{3}{|c|}{ Score Level } & \multirow[t]{2}{*}{ Total } & \\
\hline & & $30-26$ & $25-20$ & $19-10$ & & \\
\hline \multirow[t]{4}{*}{ Nature of work } & \multirow[t]{2}{*}{ Hand work } & 5 & 6 & 4 & 15 & \multirow[t]{6}{*}{.019} \\
\hline & & $33.3 \%$ & $40.0 \%$ & $26.7 \%$ & $100.0 \%$ & \\
\hline & \multirow[t]{2}{*}{ Mental work } & 12 & 3 & 0 & 15 & \\
\hline & & $80.0 \%$ & $20.0 \%$ & $0.0 \%$ & $100.0 \%$ & \\
\hline \multirow{2}{*}{\multicolumn{2}{|c|}{ Total }} & 17 & 9 & 4 & 30 & \\
\hline & & $56.7 \%$ & $30.0 \%$ & $13.3 \%$ & $100.0 \%$ & \\
\hline
\end{tabular}




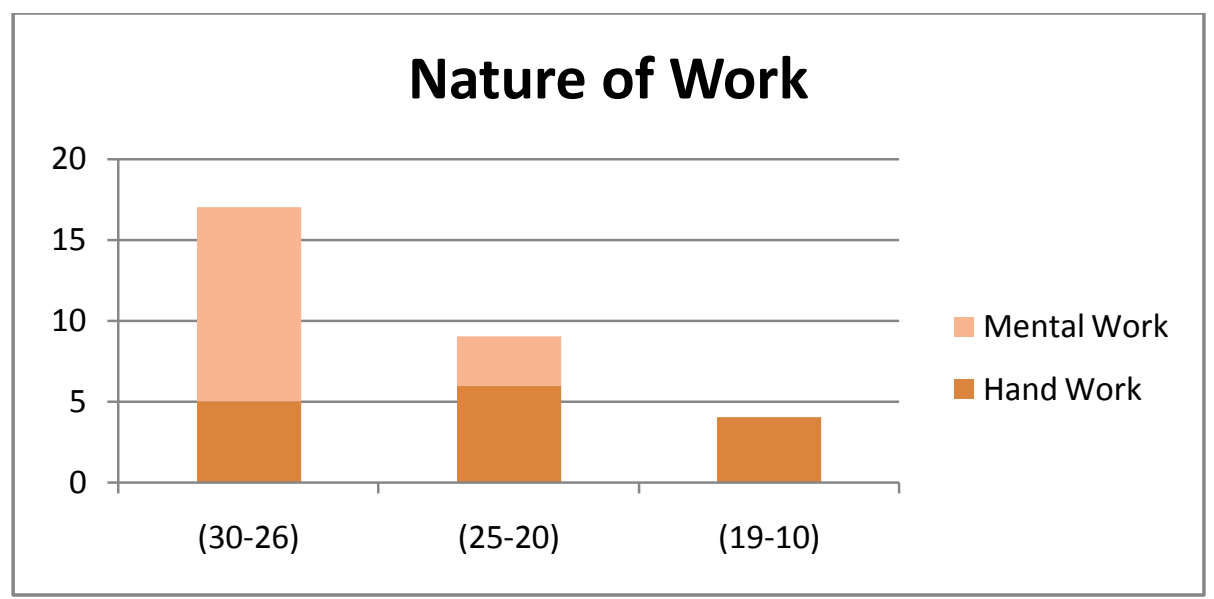

Table 7, Figure 7

Showed that individuals who participated in mental work had a score of (30-25) with a percentage of (80\%) where individuals who participated in physical labor scored in the range of (25-20) with a percentage of $(40 \%)$

The $\mathrm{P}$ value indicates that a significant risk factor was detected.

Monthly income * Score Level

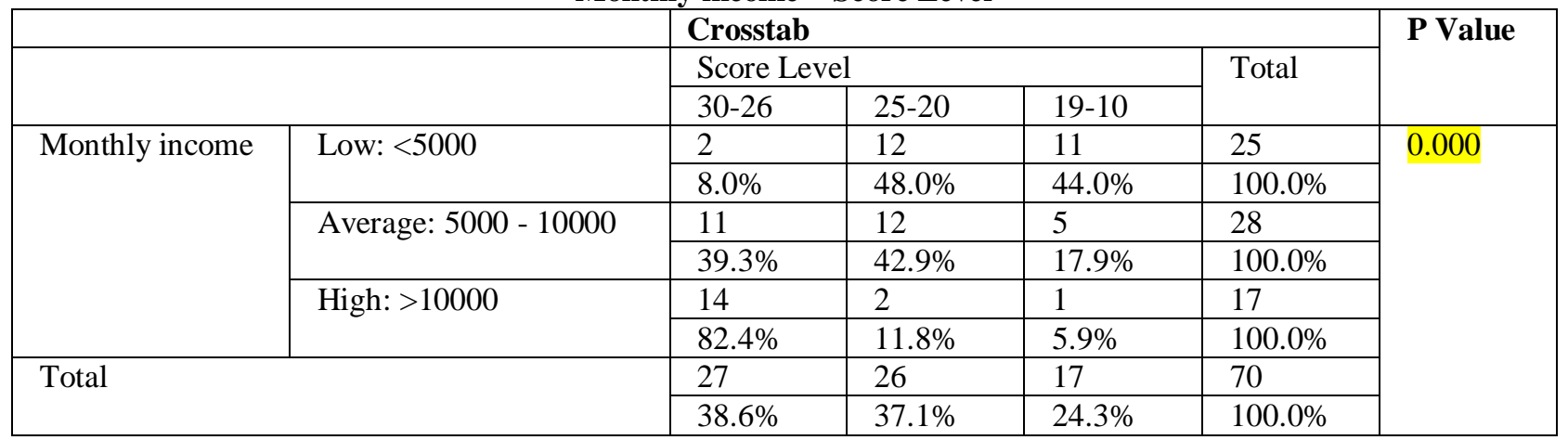

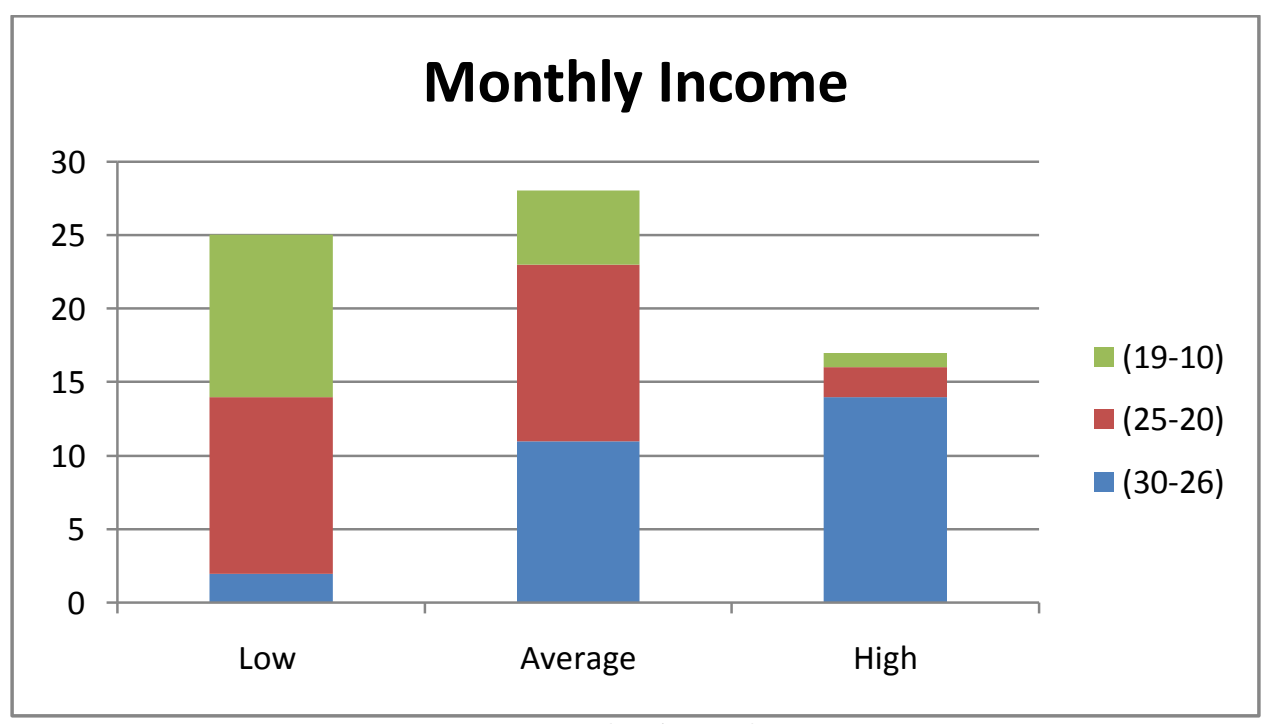

Table 8, Figure 8

Showed that individuals with low income had scored in the range of (25-20) with a percentage of (48\%) and in the range (19-10) with a percentage of (44\%). Where individuals with average income scored in the ranges of (30-20) and individuals with high income scored in the range (30-26) with a percentage of (82.4\%)

The $P$ value indicates that a significant risk factor was detected. 
Source of income * Score Level

\begin{tabular}{|c|c|c|c|c|c|c|}
\hline & & \multicolumn{4}{|c|}{ Crosstab } & \multirow[t]{3}{*}{ P Value } \\
\hline & & \multicolumn{3}{|c|}{ Score Level } & \multirow[t]{2}{*}{ Total } & \\
\hline & & $30-26$ & $25-20$ & $19-10$ & & \\
\hline \multirow[t]{4}{*}{ Source of income } & \multirow[t]{2}{*}{ The individual } & 18 & 12 & 7 & 37 & \multirow[t]{6}{*}{0.123} \\
\hline & & $48.6 \%$ & $32.4 \%$ & $18.9 \%$ & $100.0 \%$ & \\
\hline & \multirow{2}{*}{ The family } & 8 & 14 & 10 & 32 & \\
\hline & & $25.0 \%$ & $43.8 \%$ & $31.3 \%$ & $100.0 \%$ & \\
\hline \multirow{2}{*}{\multicolumn{2}{|c|}{ Total }} & 26 & 26 & 17 & 69 & \\
\hline & & $37.7 \%$ & $37.7 \%$ & $24.6 \%$ & $100.0 \%$ & \\
\hline
\end{tabular}

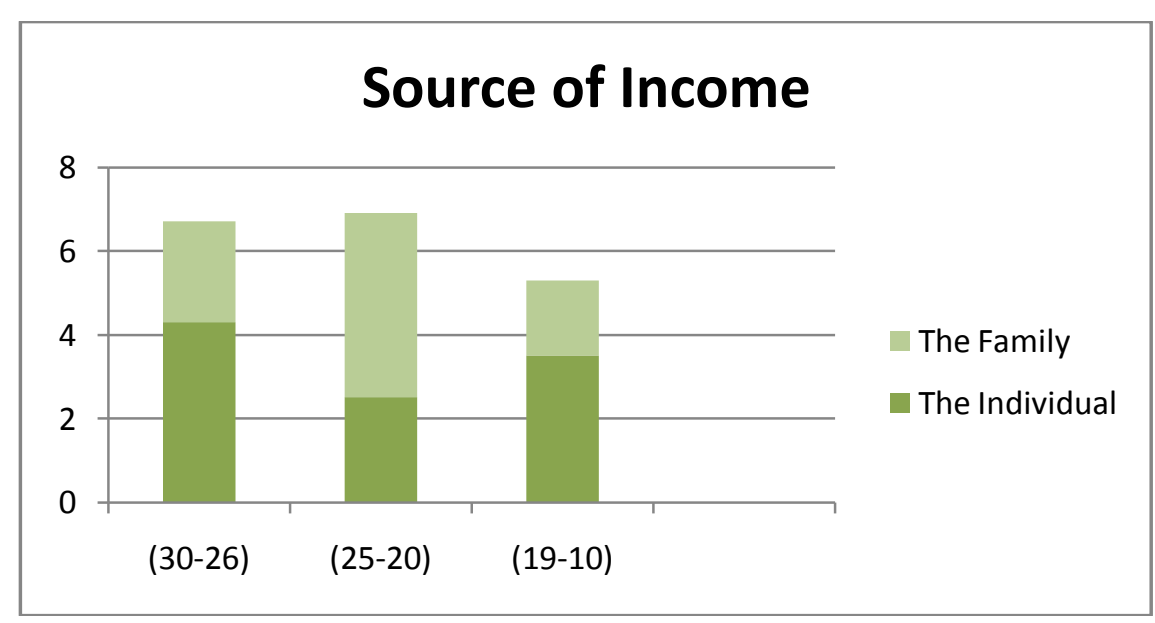

Table 9, Figure 9

Showed that when the individuals themselves earned the income they tend to score in the range (30-26) with a percentage of (48.6\%) Where when the family earned the income, the individuals scored in the range (25-20) with a percentage of $(43.8 \%)$

However, the $\mathrm{P}$ value indicates that no significant risk factor was detected.

Physical activity * Score Level

\begin{tabular}{|c|c|c|c|c|c|c|}
\hline & & \multicolumn{4}{|c|}{ Crosstab } & \multirow[t]{3}{*}{ P Value } \\
\hline & & \multicolumn{3}{|c|}{ Score Level } & \multirow[t]{2}{*}{ Total } & \\
\hline & & $30-26$ & $25-20$ & $19-10$ & & \\
\hline \multirow{4}{*}{ Physical activity } & \multirow{2}{*}{ Yes } & 18 & 16 & 6 & 40 & \multirow[t]{6}{*}{0.078} \\
\hline & & $45.0 \%$ & $40.0 \%$ & $15.0 \%$ & $100.0 \%$ & \\
\hline & \multirow[t]{2}{*}{ No } & 9 & 11 & 12 & 32 & \\
\hline & & $28.1 \%$ & $34.4 \%$ & $37.5 \%$ & $100.0 \%$ & \\
\hline \multirow{2}{*}{\multicolumn{2}{|c|}{ Total }} & 27 & 27 & 18 & 72 & \\
\hline & & $37.5 \%$ & $37.5 \%$ & $25.0 \%$ & $100.0 \%$ & \\
\hline
\end{tabular}

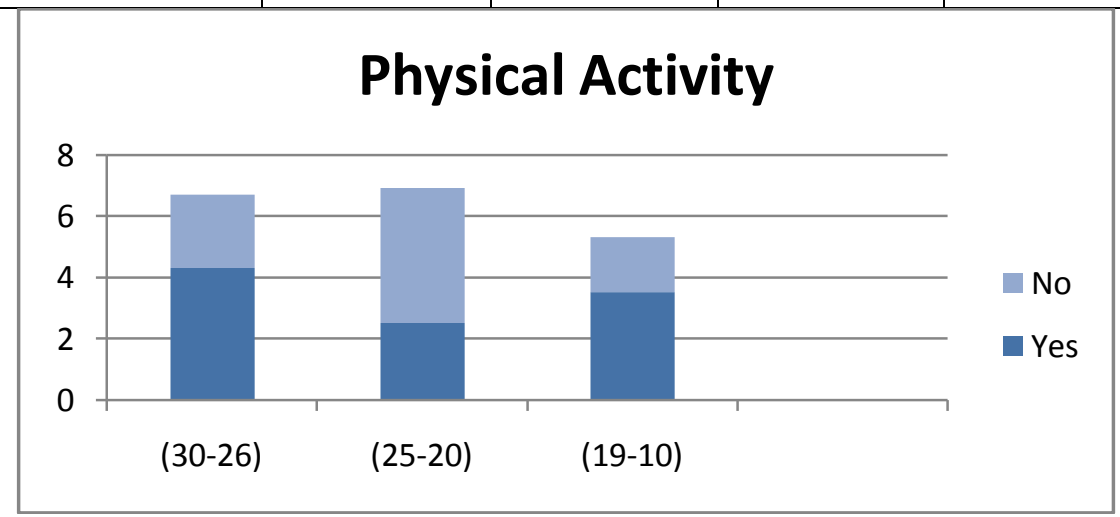

Table 10, Figure 10 
Showed that the individuals who participated in physical activity scored in the range of (30-26) with a percentage of $(45 \%)$. Where individuals who did not participated in physical activity scored in the range of (19-10) with a percentage of $(37.5 \%)$

However, the $\mathrm{P}$ value indicates that no significant risk factor was detected.

\begin{tabular}{|c|c|c|c|c|c|c|}
\hline \multicolumn{7}{|c|}{ Kind of physical activity $*$ Score Level } \\
\hline & & \multicolumn{4}{|c|}{ Crosstab } & \multirow{3}{*}{ P Value } \\
\hline & & \multicolumn{3}{|c|}{ Score Level } & \multirow[t]{2}{*}{ Total } & \\
\hline & & $30-26$ & $25-20$ & $19-10$ & & \\
\hline \multirow[t]{4}{*}{ Kind of physical activity } & \multirow{2}{*}{ Regular } & 9 & 8 & 3 & 20 & \multirow{6}{*}{1.000} \\
\hline & & $45.0 \%$ & $40.0 \%$ & $15.0 \%$ & $100.0 \%$ & \\
\hline & \multirow[t]{2}{*}{ Irregular } & 9 & 8 & 3 & 20 & \\
\hline & & $45.0 \%$ & $40.0 \%$ & $15.0 \%$ & $100.0 \%$ & \\
\hline \multirow{2}{*}{\multicolumn{2}{|c|}{ Total }} & 18 & 16 & 6 & 40 & \\
\hline & & $45.0 \%$ & $40.0 \%$ & $15.0 \%$ & $100.0 \%$ & \\
\hline
\end{tabular}

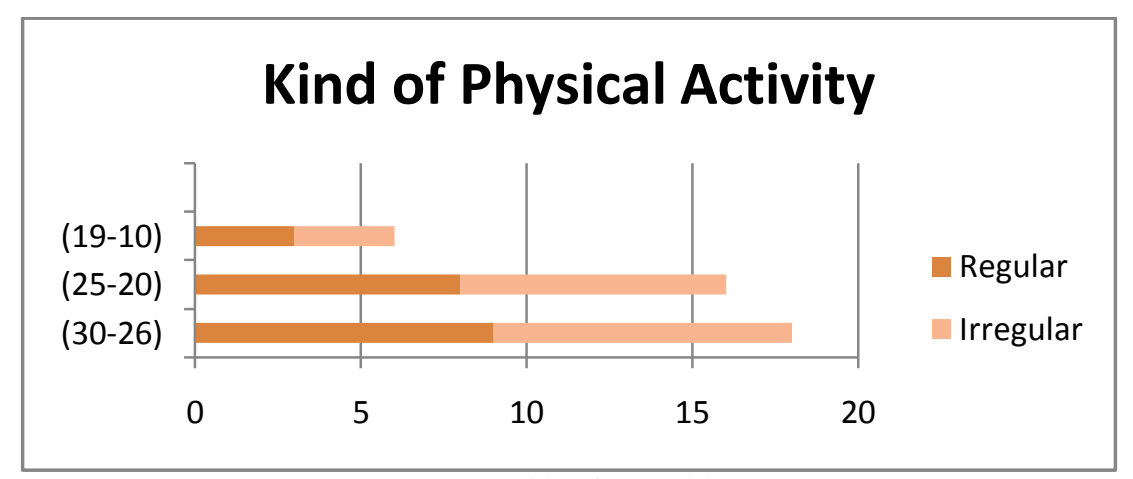

Table 11, Figure 11

Showed that there is no difference between regular and irregular physical activity.

The $\mathrm{P}$ value indicates that no risk factor was detected.

\begin{tabular}{|c|c|c|c|c|c|}
\hline \multicolumn{6}{|c|}{ Minutes per day * Score Level } \\
\hline & & \multicolumn{3}{|c|}{ Crosstab } & \multirow[t]{3}{*}{ P Value } \\
\hline & & \multicolumn{2}{|c|}{ Score Level } & \multirow[t]{2}{*}{ Total } & \\
\hline & & $30-26$ & $25-20$ & & \\
\hline \multirow[t]{8}{*}{ Minutes per day } & \multirow[t]{2}{*}{10.00} & 1 & 1 & 2 & \multirow[t]{10}{*}{.563} \\
\hline & & $50.0 \%$ & $50.0 \%$ & $100.0 \%$ & \\
\hline & \multirow[t]{2}{*}{15.00} & 1 & 0 & 1 & \\
\hline & & $100.0 \%$ & $0.0 \%$ & $100.0 \%$ & \\
\hline & \multirow[t]{2}{*}{20.00} & 0 & 1 & 1 & \\
\hline & & $0.0 \%$ & $100.0 \%$ & $100.0 \%$ & \\
\hline & \multirow[t]{2}{*}{30.00} & 4 & 5 & 9 & \\
\hline & & $44.4 \%$ & $55.6 \%$ & $100.0 \%$ & \\
\hline \multirow{2}{*}{\multicolumn{2}{|c|}{ Total }} & 6 & 7 & 13 & \\
\hline & & $46.2 \%$ & $53.8 \%$ & $100.0 \%$ & \\
\hline
\end{tabular}




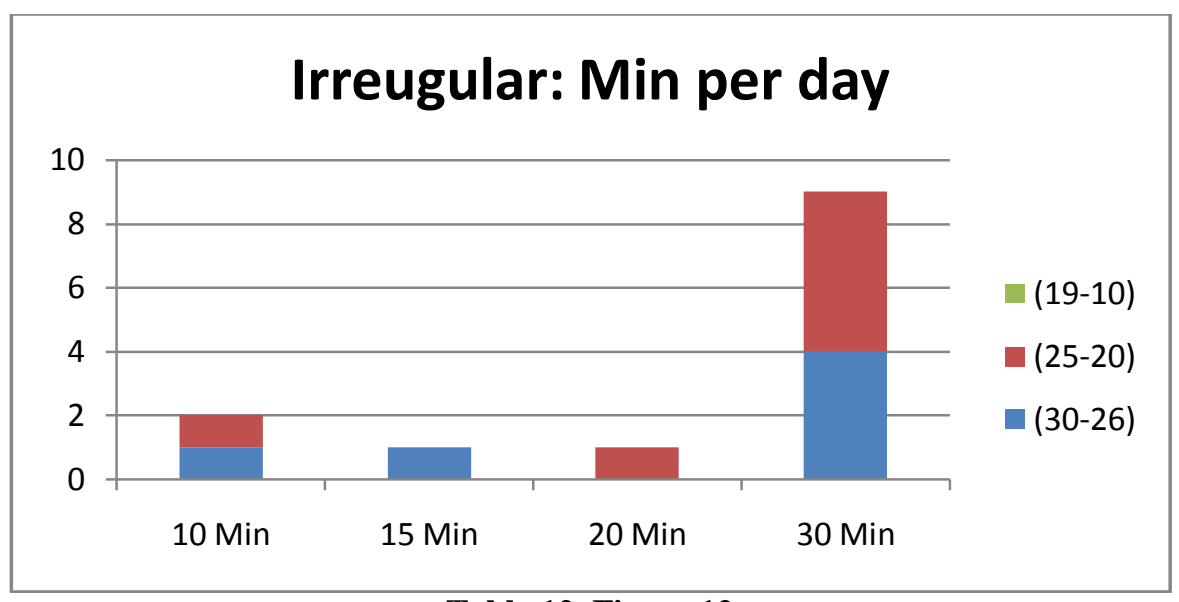

Table 12, Figure 12

Showed that individuals who participated in a physical activity everyday for less than an hour scored exclusively in the ranges of (30-20)

However, $\mathrm{P}$ value indicates that no significant risk factor was detected.

Hours per week * Score Level

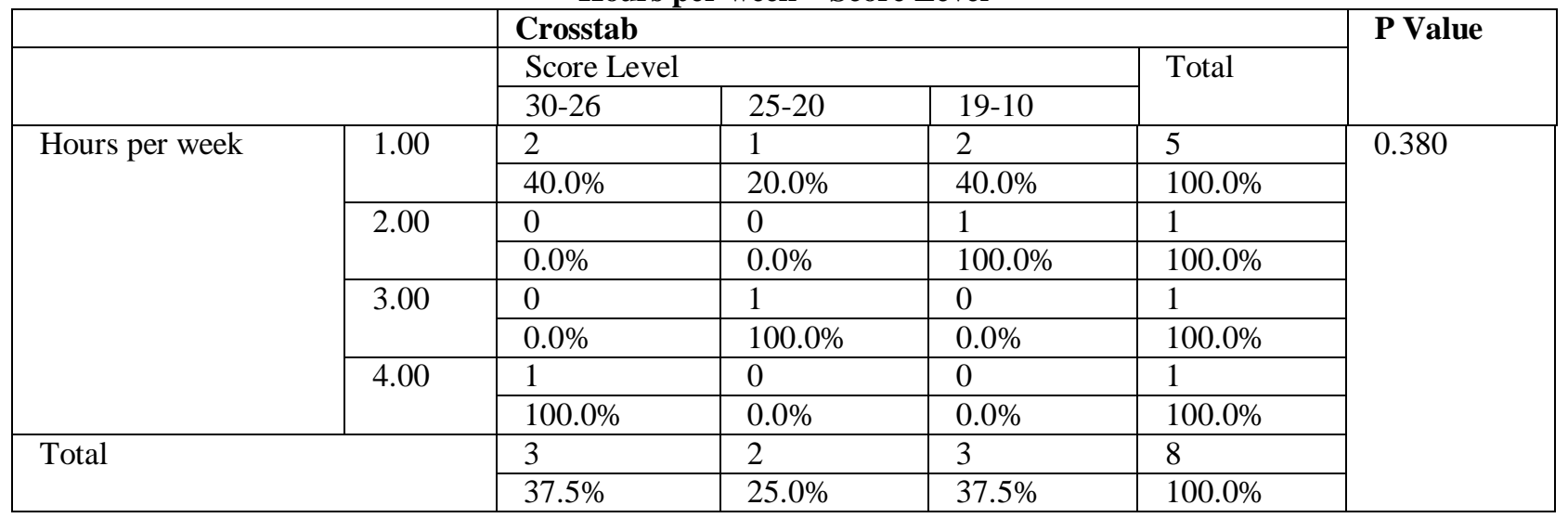

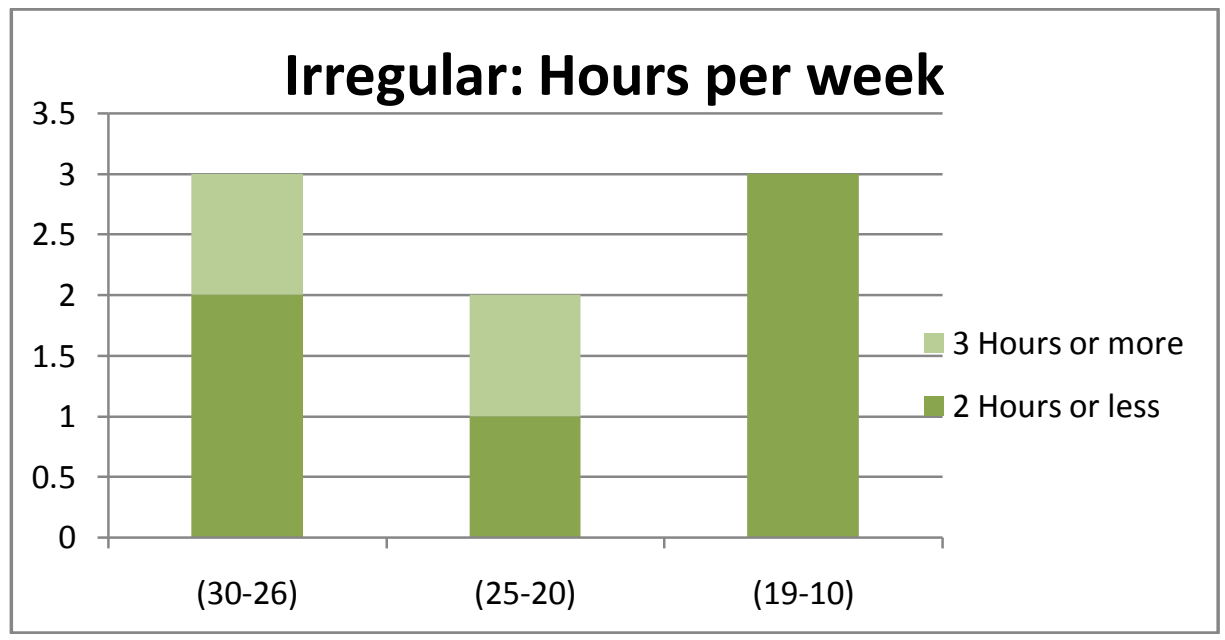

Table 13, Figure 13

Showed that individuals who exercised for 3 hours or more a week scored in the ranges of (30-20) where individuals who exercised for 2 hours or less a week scored in the range (19-10)

However, the $\mathrm{P}$ value indicates that no significant risk factor was detected. 


\section{Medical history * Score Level}

\begin{tabular}{|c|c|c|c|c|c|}
\hline & & \multicolumn{4}{|l|}{ Crosstab } \\
\hline & & \multicolumn{3}{|c|}{ Score Level } & \multirow[t]{2}{*}{ Total } \\
\hline & & $30-26$ & $25-20$ & 19-10 & \\
\hline \multirow{10}{*}{ Medical history } & \multirow{2}{*}{ Diabetes } & 8 & 9 & 7 & 24 \\
\hline & & $33.3 \%$ & $37.5 \%$ & $29.2 \%$ & $100.0 \%$ \\
\hline & \multirow[t]{2}{*}{ Heart disease } & 0 & 5 & 3 & 8 \\
\hline & & $0.00 \%$ & $62.5 \%$ & $37.5 \%$ & $100.0 \%$ \\
\hline & \multirow[t]{2}{*}{ High blood pressure } & 8 & 5 & 10 & 23 \\
\hline & & $34.8 \%$ & $21.7 \%$ & $43.5 \%$ & $100.0 \%$ \\
\hline & \multirow[t]{2}{*}{ High cholesterol } & 8 & 5 & 7 & 20 \\
\hline & & $40.0 \%$ & $25.0 \%$ & $35.0 \%$ & $100.0 \%$ \\
\hline & \multirow[t]{2}{*}{ None } & 9 & 9 & 1 & 19 \\
\hline & & $47.4 \%$ & $47.4 \%$ & $5.3 \%$ & $100.0 \%$ \\
\hline \multirow{2}{*}{\multicolumn{2}{|c|}{ Total }} & 33 & 33 & 28 & 94 \\
\hline & & $35.10 \%$ & $35.10 \%$ & $29.78 \%$ & $100.0 \%$ \\
\hline
\end{tabular}

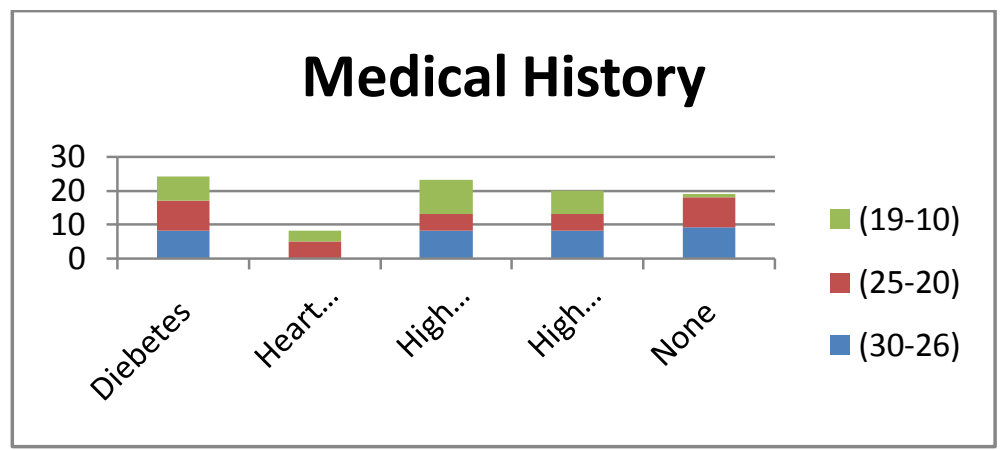

Table 14, Figure 14

Showed a close relation between heart disease, high blood pressure, high cholesterol and a low score on the test.

Do you use any medications to control these diseases? * Score Level

\begin{tabular}{|c|c|c|c|c|c|c|}
\hline & & \multicolumn{4}{|c|}{ Crosstab } & \multirow[t]{3}{*}{ P Value } \\
\hline & & \multicolumn{3}{|c|}{ Score Level } & \multirow[t]{2}{*}{ Total } & \\
\hline & & $30-26$ & $25-20$ & $19-10$ & & \\
\hline \multirow{4}{*}{$\begin{array}{l}\text { Do you use any medications to } \\
\text { control these diseases? }\end{array}$} & Yes & 11 & 15 & 14 & 40 & \multirow[t]{6}{*}{0.048} \\
\hline & & $27.5 \%$ & $37.5 \%$ & $35.0 \%$ & $100.0 \%$ & \\
\hline & No & 5 & 0 & 2 & 7 & \\
\hline & & $71.4 \%$ & $0.0 \%$ & $28.6 \%$ & $100.0 \%$ & \\
\hline \multirow{2}{*}{\multicolumn{2}{|c|}{ Total }} & 16 & 15 & 16 & 47 & \\
\hline & & $34.0 \%$ & $31.9 \%$ & $34.0 \%$ & $100.0 \%$ & \\
\hline
\end{tabular}

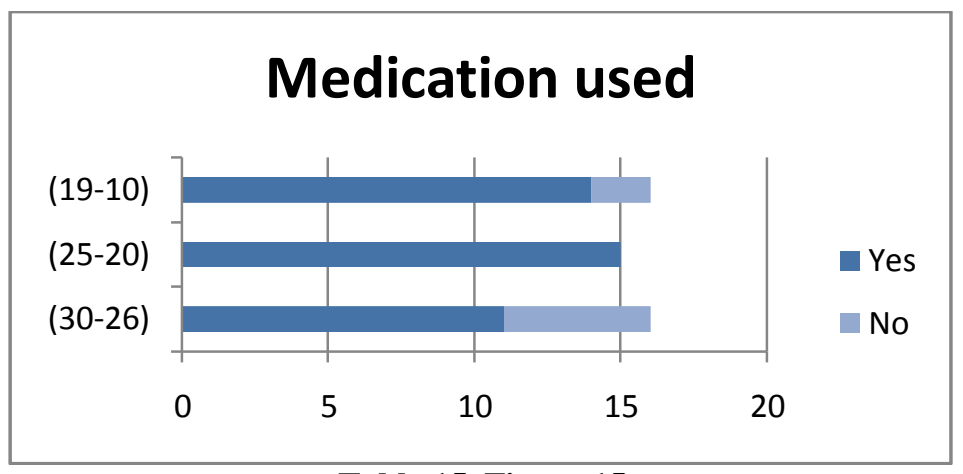

Table 15, Figure 15

Showed that individuals who used medication for their diseases scored in the range (25-20) with a percentage of (37.5\%) Where individuals who did not use medication scored in the range of (30-26) with a percentage of (71.4\%) The $\mathrm{P}$ value indicates that a significant risk factor was detected. 
Do you take these medications regularly? * Score Level

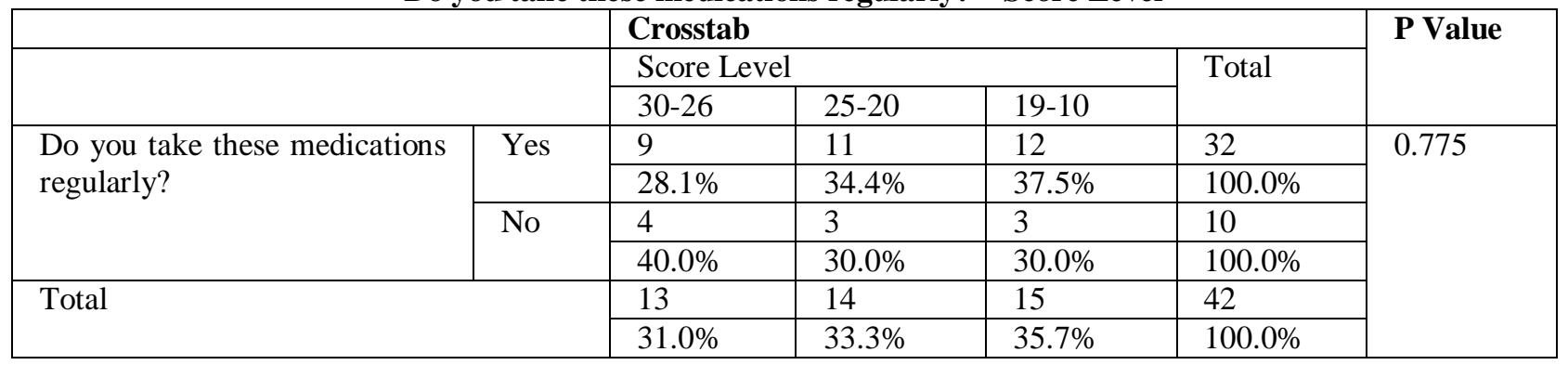

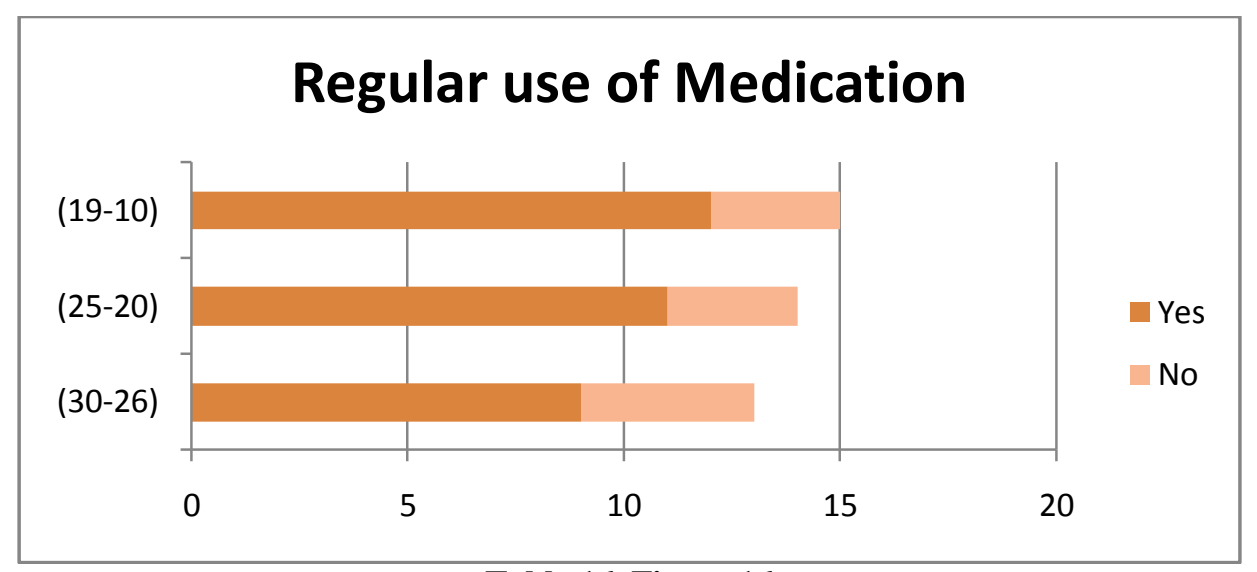

Table 16, Figure 16

Showed that individuals who took their medication regularly scored in the range (19-10) with a percentage of (37.5\%) Where the individuals who did not take their medication regularly scored in the range (30-26) with a percentage of $(40 \%)$

However, the $\mathrm{P}$ value indicates that no significant risk factor was detected.

BMI * Score Level

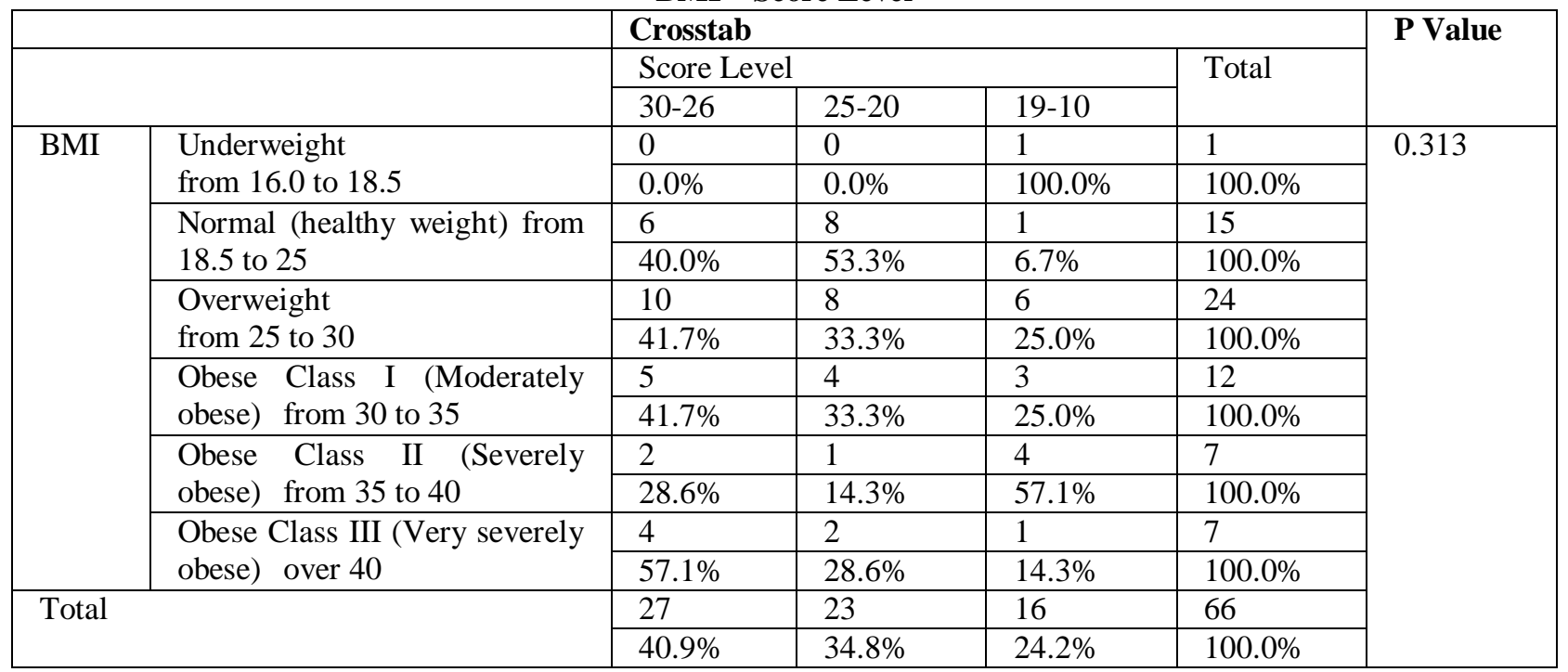




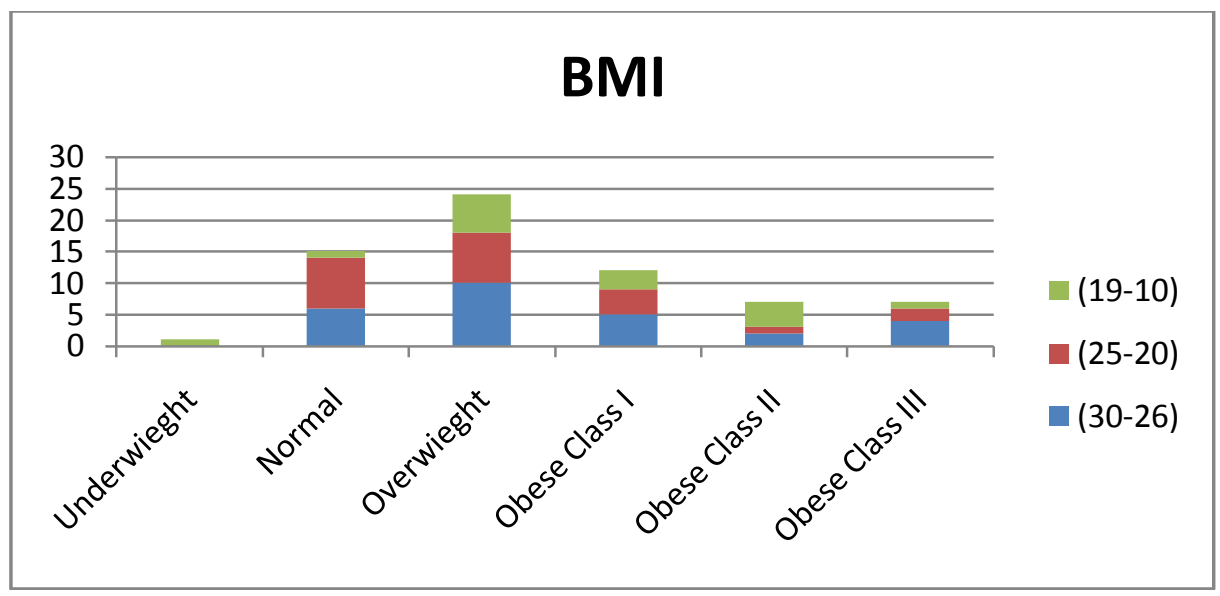

Table 17, Figure 17

Showed that normal weight individuals scored in the range (25-20) with a percentage of (53.3\%) Where individuals of the obese II class scored in the range (19-10) with a percentage of (57.1\%) And individuals in the obese class III scored in the range (30-26) with a percentage of a $(57.1 \%)$

However, the $\mathrm{P}$ value indicates that no significant risk factor was detected.

Condition of living * Score Level

\begin{tabular}{|c|c|c|c|c|c|c|}
\hline & & \multicolumn{4}{|c|}{ Crosstab } & \multirow[t]{3}{*}{ P Value } \\
\hline & & \multicolumn{3}{|c|}{ Score Level } & \multirow[t]{2}{*}{ Total } & \\
\hline & & $30-26$ & $25-20$ & $19-10$ & & \\
\hline \multirow[t]{4}{*}{ Condition of living } & \multirow[t]{2}{*}{ With family } & 26 & 26 & 16 & 68 & \multirow[t]{6}{*}{0.494} \\
\hline & & $38.2 \%$ & $38.2 \%$ & $23.5 \%$ & $100.0 \%$ & \\
\hline & \multirow[t]{2}{*}{ Alone } & 1 & 1 & 2 & 4 & \\
\hline & & $25.0 \%$ & $25.0 \%$ & $50.0 \%$ & $100.0 \%$ & \\
\hline \multirow{2}{*}{\multicolumn{2}{|c|}{ Total }} & 27 & 27 & 18 & 72 & \\
\hline & & $37.5 \%$ & $37.5 \%$ & $25.0 \%$ & $100.0 \%$ & \\
\hline
\end{tabular}

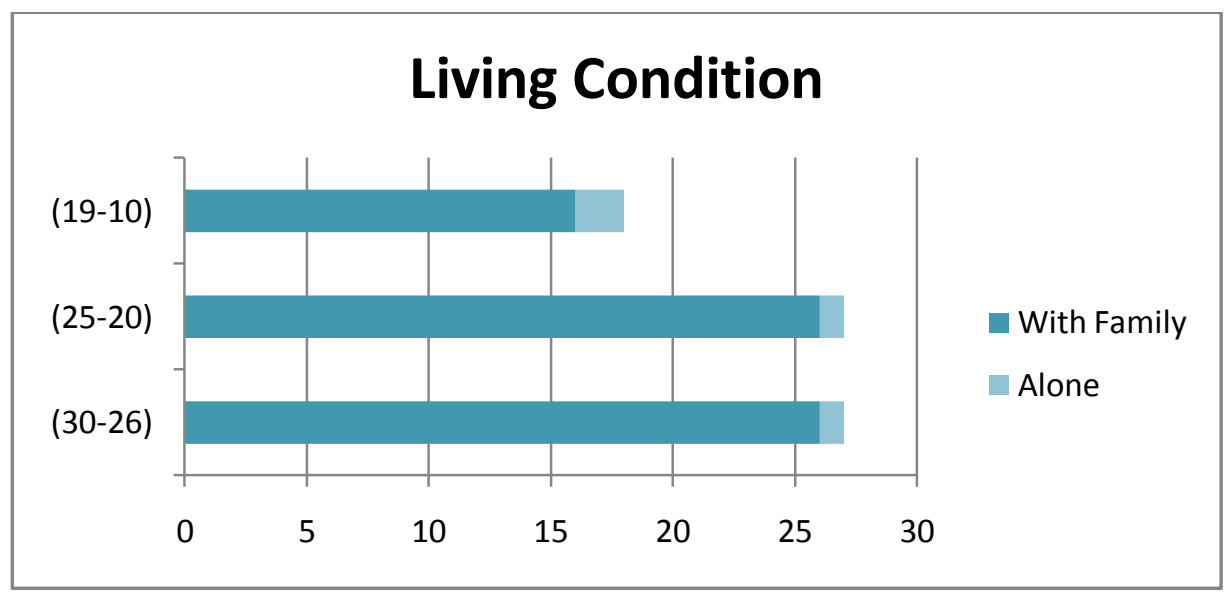

Table 18, Figure 18

Showed those individuals who lived with family members scored in the ranges of $(30-20)$ where individuals who lived alone scored in the ranges of (25-10)

However, the $\mathrm{P}$ value indicates that no significant risk factor was detected. 


\begin{tabular}{|c|c|c|c|c|c|}
\hline \multicolumn{6}{|c|}{ Social activity * Score Level } \\
\hline & & \multicolumn{4}{|c|}{ Crosstab } \\
\hline & & \multicolumn{3}{|c|}{ Score Level } & \multirow{2}{*}{ Total } \\
\hline & & $30-26$ & $25-20$ & $19-10$ & \\
\hline \multirow[t]{8}{*}{ Social activity } & \multirow[t]{2}{*}{ Family visits } & 25 & 26 & 14 & 65 \\
\hline & & $38.5 \%$ & $40.0 \%$ & $21.5 \%$ & $100.0 \%$ \\
\hline & \multirow[t]{2}{*}{ Sport club } & 2 & 0 & 0 & 2 \\
\hline & & $100.0 \%$ & $0.00 \%$ & $0.00 \%$ & $100.0 \%$ \\
\hline & \multirow[t]{2}{*}{ Social club } & 4 & 0 & 0 & 4 \\
\hline & & $100.0 \%$ & $0.00 \%$ & $0.00 \%$ & $100.0 \%$ \\
\hline & \multirow[t]{2}{*}{ None } & 2 & 1 & 4 & 7 \\
\hline & & $28.6 \%$ & $14.3 \%$ & $57.1 \%$ & $100.0 \%$ \\
\hline \multirow{2}{*}{\multicolumn{2}{|c|}{ Total }} & 33 & 27 & 18 & 78 \\
\hline & & $42.30 \%$ & $34.61 \%$ & $23.07 \%$ & $100.0 \%$ \\
\hline
\end{tabular}

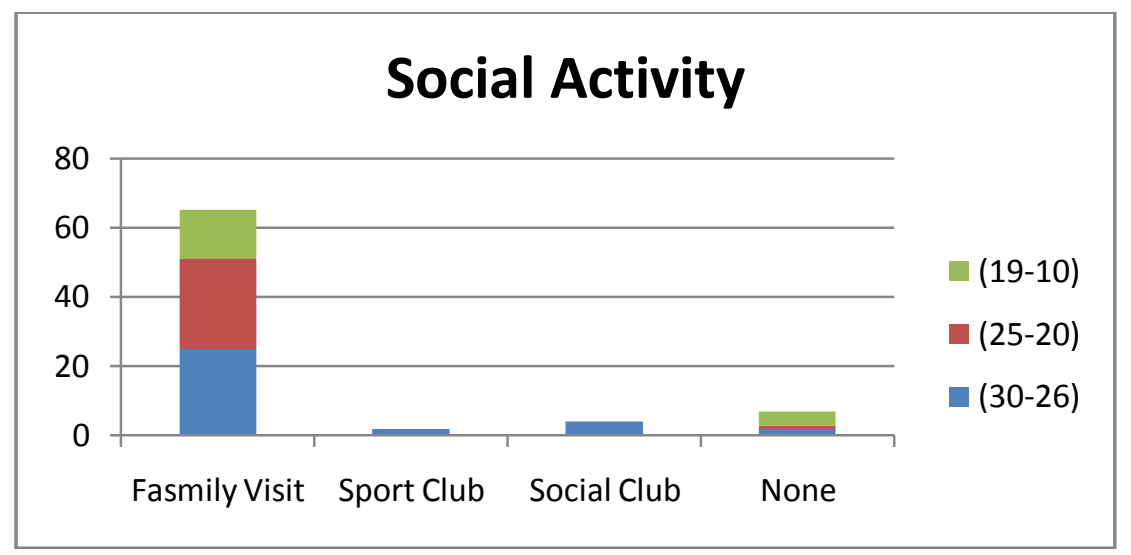

Table 19, Figure 19

Showed that there was a relation between individuals how had a high score (30-20) and those how participated in social activity i.e. (family visits, sport club, social club) While there was a relation between individuals with a low score (19-10) and those who engaged in no social activities.

Do you have a family member who's been diagnosed with Alzheimer's? * Score Level

\begin{tabular}{|c|c|c|c|c|c|c|}
\hline & & \multicolumn{4}{|c|}{ Crosstab } & \multirow[t]{3}{*}{ P Value } \\
\hline & & \multicolumn{3}{|c|}{ Score Level } & \multirow[t]{2}{*}{ Total } & \\
\hline & & $30-26$ & $25-20$ & $19-10$ & & \\
\hline \multirow{4}{*}{$\begin{array}{l}\text { Do you have a family member } \\
\text { who's been diagnosed with } \\
\text { Alzheimer's? }\end{array}$} & \multirow[t]{2}{*}{ Yes } & 5 & 4 & 4 & 13 & \multirow[t]{6}{*}{0.816} \\
\hline & & $38.5 \%$ & $30.8 \%$ & $30.8 \%$ & $100.0 \%$ & \\
\hline & \multirow[t]{2}{*}{ No } & 22 & 23 & 14 & 59 & \\
\hline & & $37.3 \%$ & $39.0 \%$ & $23.7 \%$ & $100.0 \%$ & \\
\hline \multirow{2}{*}{\multicolumn{2}{|c|}{ Total }} & 27 & 27 & 18 & 72 & \\
\hline & & $37.5 \%$ & $37.5 \%$ & $25.0 \%$ & $100.0 \%$ & \\
\hline
\end{tabular}




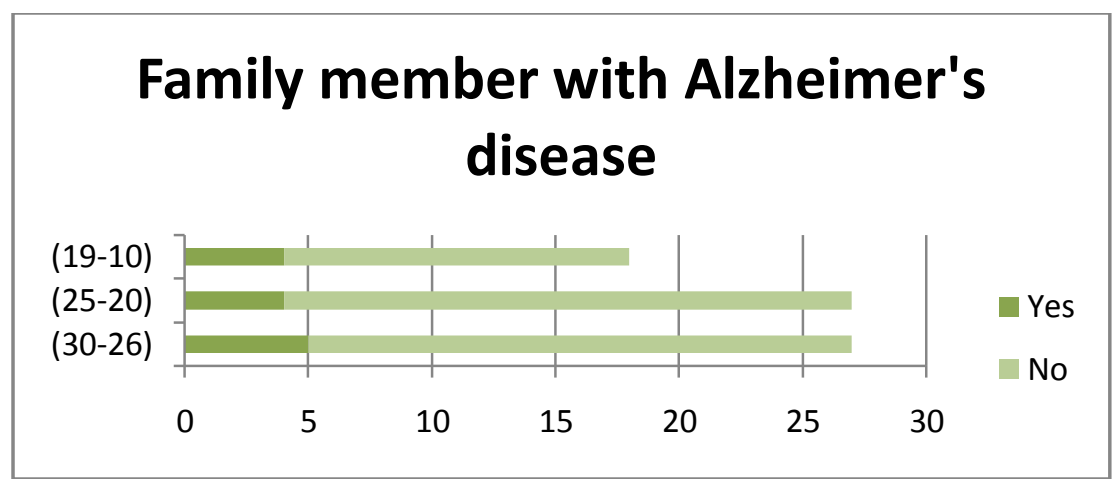

Table 20, Figure 20

Showed that individuals who had a family member diagnosed with Alzheimer's disease scored in the ranges of (30-

20) Where individuals who did not have a family member with the disease also scored in the same range. No significant risk factor was detected.

\section{Conclusion:-}

We concluded the following:

1. Differences in education level, employment status, type of work, monthly income, chronic diseases association, social activity and use of medications significantly affected the AD risk score for individuals from 50 to 80 years of age.

2. Individuals with higher education had significantly higher risk scores than their counterparts.

3. Employed individuals, and those with jobs that require mental effort had significantly higher risk scores than their unemployed and physical workers respectively.

4. Individuals with higher monthly income had significantly higher risk scores than the ones with low income.

5. Individuals who have do not have chronic diseases had significantly higher risk scores than other individuals who had chronic disease such as DM, HTN and heart disease.

6. Individuals who participated more in social activities had significantly higher risk scores than their counterparts.

7. Individuals who did not use medications had significantly higher risk scores than individuals who used medication.

8. Effect of age, sex, marital status on the AD risk score was statically insignificant.

\section{Recommendation:-}

The impact of AD in Saudi Arabia deserves further epidemiological and clinical research to enable early detection, treatment, and caregiver support. Education of individuals at risk about $\mathrm{AD}$ and its prevention via seminars, internet, TV, PHC health care providers and health pamphlets about measures to delay the development, such efforts will no doubt promote greater awareness, refine the policy agenda, and lead to a call for concerted action.

\section{Acknowledgment:-}

This research was supervised by Dr. Khadiga Dandash. We would like to show our gratitude to her, for providing us with insight and expertise that greatly assisted the research.

\section{References:-}

1. Alzheimer's association, Retrieved January 21, 2014. www.m.alz.org.

2. mhGAP (2013, June). WHO Mental Health Gap Action Programme (mhGAP). Retrieved January 21, 2014, http://www.who.int/mental_health/mhgap/en.

3. WHO (1992). International statistical classification of diseases and related health problems, 10th Revision.Geneva, World Health Organization, 1992.

4. Tana, S. (2013, February 20). Priority Medicines for Europe and the World "A Public Health Approach to Innovation" Update on 2004 Background.

5. Saudi Alzheimer's disease association, Retrieved January 21, 2014. http://www.alz.org.sa/en_content/about_sada/about_sada.htm 
Instructions: Score one point for each correct response within each question or activity.

\begin{tabular}{|c|c|c|}
\hline $\begin{array}{l}\text { Maximum } \\
\text { Score }\end{array}$ & $\begin{array}{l}\text { Patient's } \\
\text { Score }\end{array}$ & Questions \\
\hline 5 & & "What is the year? Season? Date? Day? Month?" \\
\hline 5 & & "Where are we now? State? County? Town/city? Hospital? Floor?" \\
\hline 3 & & $\begin{array}{l}\text { The examiner names three unrelated objects clearly and slowly, then } \\
\text { the instructor asks the patient to name all three of them. The patient's } \\
\text { response is used for scoring. The examiner repeats them until patient } \\
\text { learns all of them, if possible. }\end{array}$ \\
\hline 5 & & $\begin{array}{l}\text { "I would like you to count backward from } 100 \text { by sevens." }(93,86,79 \text {, } \\
72,65, \ldots) \\
\text { Alternative: "Spell WORLD backwards." (D-L-R-O-W) }\end{array}$ \\
\hline 3 & & $\begin{array}{l}\text { "Earlier I told you the names of three things. Can you tell me what } \\
\text { those were?" }\end{array}$ \\
\hline 2 & & $\begin{array}{l}\text { Show the patient two simple objects, such as a wristwatch and a pencil, } \\
\text { and ask the patient to name them. }\end{array}$ \\
\hline 1 & & "Repeat the phrase: 'No ifs, ands, or buts." \\
\hline 3 & & $\begin{array}{l}\text { "Take the paper in your right hand, fold it in half, and put it on the floor." } \\
\text { (The examiner gives the patient a piece of blank paper.) }\end{array}$ \\
\hline 1 & & $\begin{array}{l}\text { "Please read this and do what it says." (Written instruction is "Close } \\
\text { your eyes.") }\end{array}$ \\
\hline 1 & & $\begin{array}{l}\text { "Make up and write a sentence about anything." (This sentence must } \\
\text { contain a noun and a verb.) }\end{array}$ \\
\hline 1 & & $\begin{array}{l}\text { "Please copy this picture." (The examiner gives the patient a blank } \\
\text { piece of paper and asks him/her to draw the symbol below. All } 10 \\
\text { angles must be present and two must intersect.) }\end{array}$ \\
\hline 30 & & TOTAL \\
\hline
\end{tabular}


1. Score

2. Age

3. Sex

$\bigcirc$ male

Female

4. Marital status

Married

Not married

5. Residence

Big city

Small city

Rural

6. Education level

Illiterate

Can read and write

Elementary school

Middle school

High school

College

7. Employment Status

Yes

No

8. Nature of work

Hand work

Mental work

9. Monthly income

Low: $<5000$

Average: 5000 - 10000

High: $>10000$

10. Source of income

The individual

The family

11. Physical activity

Yes

No

12. Kind of physical activity

Kind of physical activity Regular

Irregular

13. Regular: physical activity for 10 minutes 
Intense: Running/football/swimming

Mild: lifting things/ house chores

Walking

14. Irregular: Duration of physical activity

Hours per day

Minutes per

day

Hours per week

Minutes per

week

15. Medical history

Diabetes

Heart disease

High blood pressure

High cholesterol

None

16. Do you use any medications to control these diseases?

Yes

No

17. Do you take these medications regularly?

Yes

No

18. BMI

Very severely underweight less than 15

Severely underweight from 15.0 to 16.0

Underweight from 16.0 to 18.5

Normal (healthy weight) from 18.5 to 25

Overweight from 25 to 30

Obese Class I (Moderately obese) from 30 to 35

Obese Class II (Severely obese) from 35 to 40

Obese Class III (Very severely obese) over 40

19. Condition of living

With family

Alone

\section{Social activity}

Social activity Family visits

Sport club 
Social club

None

21. Do you have a family member who's been diagnosed with Alzheimer's?

$\bigcirc$ Yes

No 